Revista Monografias Ambientais

Santa Maria, v. 14, Ed. Especial Unipampa. 2015, p. 14-32

Revista do Centro de Ciências Naturais e Exatas - UFSM

ISSN : 22361308

\title{
Recuperação ambiental na disposição de estéril em mineração de calcário
}

\author{
Environmental recovery in sterile waste pile in limestone mining
}

\author{
Evandro Gomes dos Santos ${ }^{1}$, Raul Oliveira Neto' ${ }^{2}$ Luciana Arnt Abichequer'2, Luis Eduardo de \\ Souza $^{2}$, Renato Marques ${ }^{1}$, Ítalo Gomes Gonçalves ${ }^{2}$
}

${ }^{1}$ Tecnólogo em Mineração, Universidade Federal do Pampa, Caçapava do Sul,RS, Brasil

${ }^{2}$ Engenheiro(a) de Minas/Professor do Programa de Pós-Graduação em Tecnologia Mineral (PPGTM), Universidade Federal do Pampa, Caçapava do Sul, RS, Brasil

\begin{abstract}
Resumo
Os estéreis e os rejeitos são os principais resíduos gerados pela mineração, merecendo atenção no que diz respeito a seu correto manuseio e destinação. Apesar da lavra de calcário, comumente, compreender operações unitárias básicas, ao longo dos anos movimenta grandes volumes de estéril que é depositado em pilhas. Neste contexto, o presente trabalho visa avaliar e propor melhorias aos aspectos construtivos da pilha em estudo, identificando os impactos ambientais e propondo as medidas mitigadoras e compensatórias cabíveis. Para obtenção dos dados, foi realizado levantamento topográfico e processamento dos mesmos, primeiramente na planilha Excel e posteriormente nos softwares Surfer e Autocad. Na avaliação de impacto ambiental foi utilizada a matriz de Leopold e parâmetros da ISO 14001, definindo-se critérios de hierarquização da significância dos impactos. O levantamento geométrico realizado apontou problemas quanto à conformação de taludes $e$ bermas, apesar de fatores como altura máxima e conservação de áreas de preservação permanente estarem de acordo. Quanto à estabilidade, os valores de fator de segurança estão, em média, de acordo com a legislação, que determina um mínimo de 1,5, entretanto, alguns taludes intermediários não alcançam este valor. Há, também, zonas que não atendem às boas práticas propostas, como ângulo de talude inferior a 36므, porém, em toda a pilha não são verificados sinais de ruptura. A avaliação de impacto ambiental realizada constatou que $50 \%$ dos impactos são graves e $50 \%$ são médios, aos quais foram propostas medidas mitigadoras e compensatórias e planos de ação e monitoramento. Como conclusão, pode-se dizer que a pilha atende somente em parte às normas e boas práticas, sendo de fundamental importância a implantação das medidas e de plano de ação propostos.
\end{abstract}

Palavras-chave: recuperação ambiental, estéril, mineração, calcário.

\begin{abstract}
Overburden material and waste are the main residues generated by mining, with attention regard to its proper handling and disposal. Although the limestone extraction that comprise basic unit operations over the years moving large volumes of sterile, which is deposited in piles. In this context the present study aims to evaluate and propose improvements to the constructive aspects of the piles under study, identifying the environmental impacts and proposing mitigation and compensation measures, as appropriate. To obtain the data was carried out topographic survey and processing the same, first in the Excel worksheet, and later they were used in the Surfer and Autocad software. In the environmental impact assessment was used to Leopold matrix and ISO 14001 parameters, defining prioritization criteria of the significances impacts. The study of geometric survey indicated problems on the conformation of slopes and berms, although factors such as maximum height and the conservation of permanent preservation areas are in agreement. As for stability, the safety factors values are, on average, according to the law that determining a minimum of 1.5, however, some intermediate slopes do not reach this value. There are also areas that do not attending the proposed good practices such as slope angle of less than 36, but in the whole pile are not observed signs of rupture. The environmental impact assessment carried out revealed that $50 \%$ of impacts are severe and $50 \%$ are medium, which were proposed mitigation and compensation measures and action plans and monitoring. In conclusion it can be said that the pile attending only in part the standards and best practices, which is essential in the implementation of the measures and the action plan proposed.
\end{abstract}

Keywords: environmental recovery, sterile, mining, limestone. 


\section{Introdução e objetivos}

O calcário apresenta uma grande variedade de usos, desde matéria prima para a construção civil, material para agregados, matéria prima para a fabricação de cal, fonte de ligante hidráulico (cal) na fabricação de cimento, e até como rocha ornamental. As rochas carbonatadas e seus produtos também são utilizados como corretivos de solos ácidos, refratários, abrasivos, matéria-prima para as indústrias de papel, plásticos, química, siderúrgica, de vidro, dentre outros (Sampaio e Almeida, 2005).

$\mathrm{Na}$ atividade de mineração existem dois tipos principais de resíduos sólidos: os estéreis e os rejeitos. Os estéreis são os materiais escavados, gerados pelas atividades de extração (ou lavra) no decapeamento da mina, não têm valor econômico e ficam geralmente dispostos em pilhas. Os rejeitos são resíduos resultantes dos processos de beneficiamento a que são submetidas às substancias minerais (Silva et al., 2011).

No caso da lavra de calcário, ainda segundo Silva (2009), por este ser um produto com valor agregado relativamente baixo, não ocorrem elevados índices de remoção ou produção de estéril. Embora este volume de estéril não seja elevado em comparação à lavra de outros minérios, ao longo dos anos é gerado um grande acumulado. É o caso da empresa Dagoberto Barcellos $\mathrm{S} / \mathrm{A}$, localizada às margens da BR 392, km 252,5, na localidade de Caieiras, Caçapava do Sul - RS (Figura 1), em atividade há quase cem anos e, na atualidade, responsável por aproximadamente $70 \%$ do mercado da cal e $25 \%$ do mercado de calcário no estado e, segundo Silva (2009), por 2,1\% do mercado nacional do calcário. Há produção de cerca de 100.000 t de produtos finais por mês (Dagoberto Barcellos, 2009), o que gera uma grande movimentação de run of mine (ROM) e, consequentemente material estéril, que é depositado em pilhas.

A pilha R8 caracteriza-se por ser a maior pilha de estéril da empresa, sendo maior até mesmo que uma das cavas, conforme a Figura 1. Por isso, requer maior atenção no que diz respeito a fatores geotécnicos de estabilidade, tendo em vista os enormes danos que um colapso da mesma poderia desencadear, principalmente, à jusante.

O presente trabalho tem como objetivo geral estudar, avaliar e propor melhorias aos aspectos construtivos da pilha, identificando os impactos ambientais e propondo as medidas mitigadoras e compensatórias cabíveis. Para isso pretende-se, como objetivos específicos, determinar a geometria da pilha (i), calcular o volume de material depositado e a área ocupada (ii), elaborar uma matriz de identificação e avaliação dos impactos ambientais da disposição de estéril (iii), propor medidas mitigadoras e compensatórias relacionadas a cada impacto (iv) e elaborar plano de ação/monitoramento das medidas/resultados (v). 


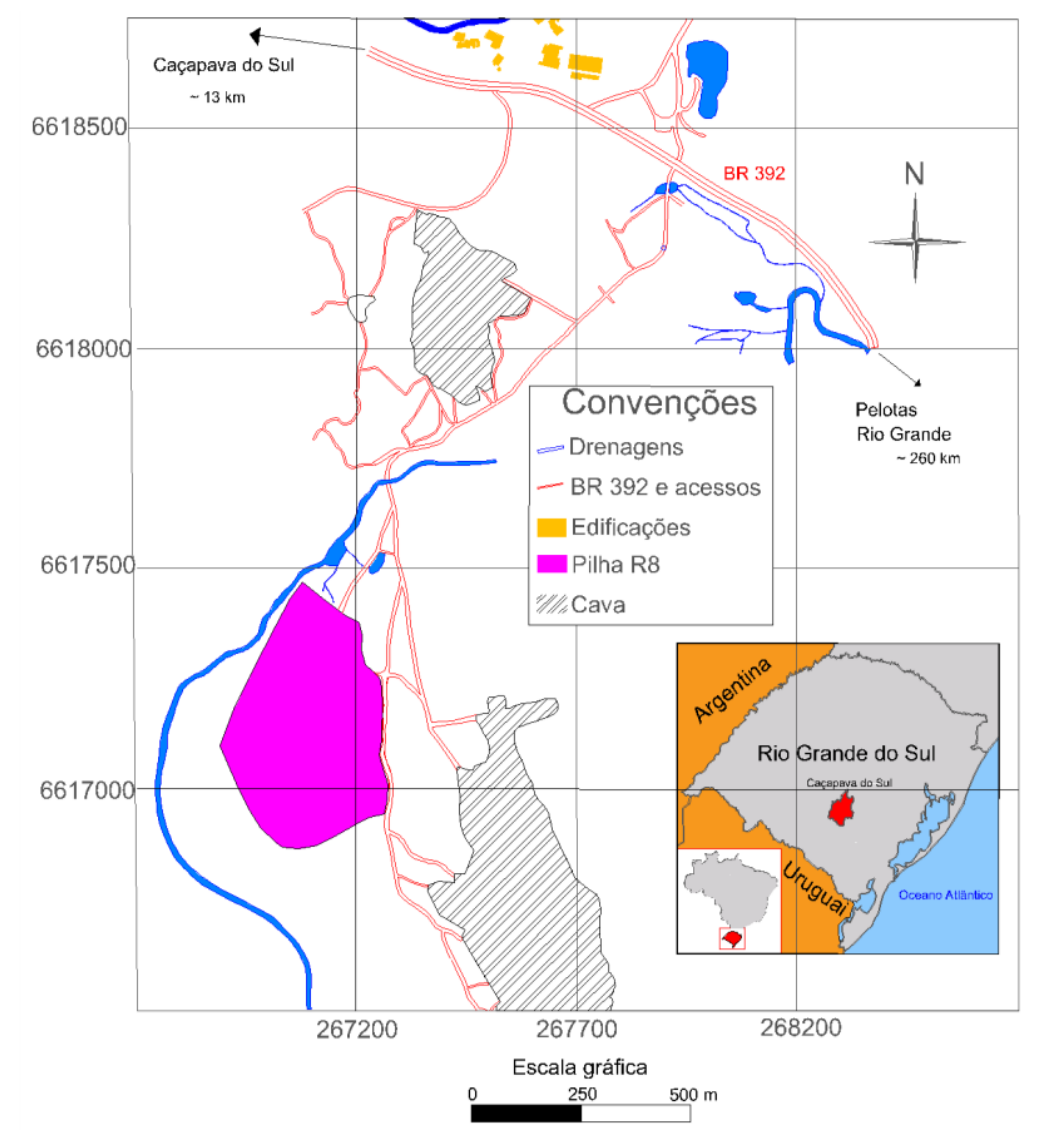

Figura 1: Mapa de localização da área de estudo. Fonte: modificado de Dorneles (2013).

\section{Estado da arte}

A remoção do capeamento superficial, ou seja, dos estéreis da mineração, gera resíduos provenientes da exploração mineral. $\mathrm{O}$ indicador dessa atividade é medido em toneladas de estéril por tonelada de ROM. Há atualmente inúmeras iniciativas de aproveitamento de rejeitos de mineração, como finos de pedreiras, e outros, que devem se multiplicar, tanto por razões econômicas (retorno sobre investimentos em valorização) quanto por razões ambientais, como a minimização de resíduos (Silva, 2009).

Segundo o trabalho de Silva et al. (2011), o sistema de deposição de estéril deve funcionar como uma estrutura projetada e implantada para acumular materiais, em caráter temporário ou definitivo, dispostos de modo planejado e controlado em condições de estabilidade geotécnica e protegido de ações erosivas, de modo mitigar a geração de resíduos e movimentos de massa. Vale ressaltar que, para Bates (2002), pilhas de estéril embora compostas por vários tipos de materiais, desde que não sejam argilas ou solos pantanosos, costumam ser estáveis.

Os movimentos de massa, segundo Maciel Filho (2008), são movimentações de volumes de solo, rocha ou mistura destes, em conjunto, diferindo da erosão que ocorre grão a grão. Os movimentos de massa classificam-se da seguinte forma (Guidicini \& Nieble, 1993 apud Maciel Filho, 2008): rastejos, corridas, escorregamentos, queda de blocos e queda de detritos. Dentre as causas de movimentos de massa citadas pelo mesmo autor, destacam-se a elevação do nível piezométrico em taludes, mudanças na geometria do sistema, efeito de vibrações e diminuição do efeito de coesão aparente.

Segundo o trabalho realizado por Petronilho (2010), para o estudo do comportamento de uma pilha de estéril, são instalados diversos instrumentos ao longo de uma dada seção representativa do empilhamento. Esta instrumentação é composta geralmente por piezômetros e marcos superficiais, 
visando à medida de poropressões e qualidade da água subterrânea e de deslocamentos, respectivamente.

No presente trabalho destaca-se como mais aplicável e significativa a utilização dos piezômetros como monitores do nível e da qualidade da água subterrânea, a montante e à jusante da pilha. Estes deverão ser construídos e desenvolvidos conforme as diretrizes da ABNT/NBR 15.495-1 (2007) e 15.945-2 (2008).

Marcos superficiais têm como objetivo detectar os deslocamentos superficiais, que podem ser de dois tipos: verticais e horizontais. Para determinar esses movimentos são instalados no mínimo três marcos fixos, ou seja, que não estarão sujeitos à influência das obras em questão, em locais estabelecidos que permitam fácil visualização destes. Os marcos superficiais são constituídos por um bloco de concreto, uma barra de aço galvanizada enterrada no maciço e um pino de aço inox no topo para servir de apoio para as réguas de nivelamento.

Sendo evidenciada a instabilidade de taludes, para Maciel Filho (2008), há quatro principais medidas a serem tomadas: mudança na geometria do talude, drenagem da água subterrânea, reforço do maciço e controle do desmonte.

Para o caso de pilhas de estéril, o método mais aplicável é a mudança na geometria dos taludes, alterando sua altura ou ângulo, pois assim se atinge a estabilização dos taludes da melhor forma com o menor custo. A maior vantagem que este método apresenta sobre os outros é que seus efeitos são permanentes, pois sua estabilização ocorre por uma mais efetiva utilização das propriedades inerentes ao maciço e pelas mudanças permanentes no sistema de forças atuante no talude.

Cita-se também como material integrante de apoio ao presente trabalho a NRM-19 - Disposição de Estéril, Rejeitos e Produtos (DNPM) e a ABNT/NBR 13.029 (1993 e 2006) - Elaboração e apresentação de projeto de disposição de estéril, em pilha, em mineração. Quanto a esta normatização podemos destacar as seguintes boas práticas, importantes no contexto do presente trabalho:

- altura máxima de bancos de $10 \mathrm{~m}$;

- largura mínima de bermas de $6 \mathrm{~m}$;

- altura máxima da pilha de $200 \mathrm{~m}$;

- ângulo de taludes inferior ao ângulo de repouso do material;

- ângulo mínimo de inclinação longitudinal das bermas de $1 \%$ e transversal de $5 \%$;

- leiras nas cristas dos bancos.

- sistema de retenção de sedimentos oriundos da erosão;

- execução da pilha de forma ascendente;

- disposição do material o mais próximo possível da cava, se possível, dentro da mesma ou em áreas já impactadas;

- deve-se evitar dispor o material em vales com inclinação superior a 18º́, áreas de preservação permanente (APP), terrenos instáveis, áreas com vegetação nativa exuberante, áreas com solo fértil;

- fator de segurança para condições normais de superfície freática de 1,5;

- fator de segurança para taludes entre bermas de 1,5;

- bermas devem ter largura suficiente para atender às considerações de drenagem e garantir acesso de equipamentos de manutenção com segurança;

- aplicação de revestimento superficial (vegetação) em bermas, plataformas e taludes;

- a disposição de estéril, rejeitos e produtos devem ser previstas no Plano de Aproveitamento Econômico - PAE;

- a construção de depósitos de estéril, rejeitos e produtos deve ser precedida de estudos geotécnicos, hidrológicos e hidrogeológicos; 
- os depósitos de estéril, rejeitos, produtos, barragens e áreas de armazenamento, assim como as bacias de decantação devem ser planejados e implantados por profissional legalmente habilitado e atender às normas em vigor;

- a estocagem definitiva ou temporária de estéril e materiais diversos provenientes da mineração deve ser realizada com o máximo de segurança e o mínimo de impacto no ambiente;

- dentro dos limites de segurança das pilhas não é permitido o estabelecimento de quaisquer edificações, exceto edificações operacionais, enquanto as áreas não forem recuperadas, a menos que as pilhas tenham estabilidade comprovada;

- construir canais periféricos a fim de desviar a drenagem natural da água da pilha.

O processo de Avaliação de Impacto Ambiental (AIA) é definido por Sánchez, 2008, como sendo um conjunto de procedimentos concatenados de maneira lógica, com a finalidade de analisar a viabilidade ambiental de projetos, planos e programas, e fundamentar uma decisão a respeito.

A AIA também tem o papel de facilitar a gestão ambiental do futuro do empreendimento. A aprovação do projeto implica certos compromissos assumidos pelo empreendedor que são delineados no estudo de impacto ambiental. A maneira de implementar as medidas mitigadoras e compensatórias, seu cronograma, a participação de outros atores na qualidade de parceiros e os indicadores de sucesso pode ser estabelecidos durante o processo, que não termina com a aprovação de uma licença, mas continua durante todo o ciclo de vida do projeto (Sánchez, 2008).

Esta AIA deve propor uma série de medidas mitigadoras e compensatórias, que são, ainda segundo Sánchez (2008), propostas com a finalidade de reduzir a magnitude ou a importância dos impactos ambientais adversos e compensar os danos que vierem a ser causados, respectivamente.

Nesta conjuntura, a aia que será realizada na pilha R8, deve contemplar todos os impactos ambientais atinentes à mesma que deveriam ter sido apresentados dentro do projeto de disposição de estéril e propor as medidas mitigadoras e compensatórias cabíveis. Dentre estas medidas, no que diz respeito às aguas, a legislação existente é a Resolução 357-2005 do CONAMA.

\section{Contexto geológico da área}

A área de estudo fica localizada na zona de contato entre o complexo metamórfico Vacacai e a suíte granítica Caçapava, conforme mostrado na figura 2. O complexo metamórfico Vacacai é composto, segundo Ribeiro et al. (1966) apud Alano (1977), de filitos, muscovita-xistos, metagrauvacas, metatufitos e metabasitos com seus derivados de variável grau de metamorfismo, como: cloritaactinolita-xistos, anfibolitos, quartzitos, quartzitos carbonosos, mármores, metarcoseos, metariolitos e meta-conglomerados.

A suíte granítica Caçapava do Sul compreende dois corpos graníticos intrusivos no Complexo Metamórfico Vacacaí. O corpo maior possui uma forma ovalada cujo eixo de maior extensão, cerca de $30 \mathrm{~km}$, está orientado segundo uma direção N-S e denomina a suíte. Esta suíte é constituída predominantemente de monzo e sienogranitos com participação subordinada de rochas de composição granodiorítica a tonalítica (CPRM, 2000). Na área de estudo as litologias encontradas são: quartzito feldspático, xistos, mármore dolomítico, diabásio e apófises graníticas, sendo esta a composição básica do material estéril proveniente do decapeamento. Entretanto, vale ressaltar a presença isolada de mineralizações associadas a intrusões ácidas e intermediárias (como dioritos e andesitos) ao longo de zonas de falha, tendo o cobre como principal elemento. É uma mineralização típica de filões, onde o cobre ocorre associado a elementos como: chumbo, zinco, ferro, ouro e, eventualmente, prata (Alano, 1977). 


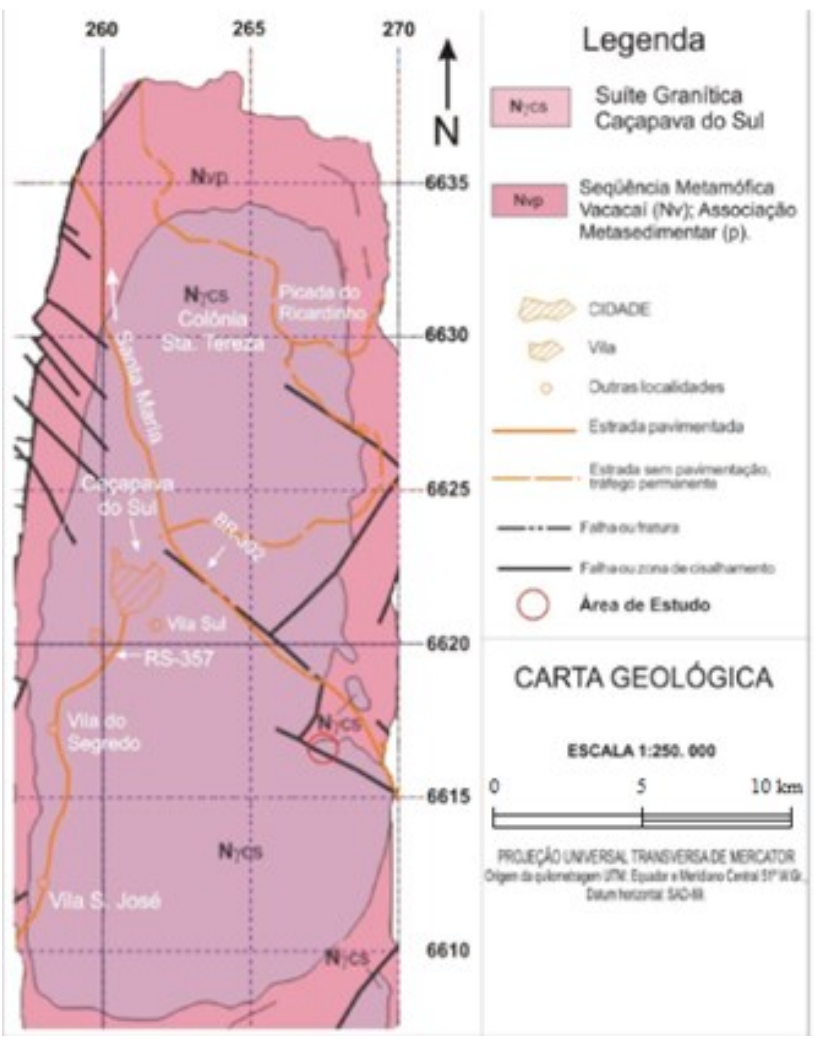

Figura 2: Mapa geológico da área de estudo. Fonte: modificado de Neto (2011).

\section{Materiais e métodos}

A primeira etapa do trabalho consistiu no levantamento topográfico da pilha, para determinação de suas características geométricas. No levantamento topográfico em campo foi utilizada uma estação total da marca Alkon ${ }^{\circledR}$ modelo MTS-802R, tendo-se coletado os pontos de cota sempre na crista e no pé das bancadas. O processamento dos dados de campo para geração das coordenadas $\mathrm{X}, \mathrm{Y}$ e Z (banco de dados) foi realizado na planilha eletrônica Excel.

Posteriormente, este banco de dados foi lançado no software Surfer ${ }^{\circledR}$ para geração do modelo de superfície e obtenção das áreas de abrangência e do volume de estéril contido, tendo-se testado os três interpoladores mais usuais: triangulação, mínima curvatura e inverso do quadrado da distância (IQD). A escolha do método mais adequado foi baseada na apreciação visual e na validação cruzada, que consiste em descartar, temporariamente, uma a uma, as amostras do banco de dados, estimando um valor para cada uma destas localizações a partir do restante das amostras. Isto permite que se possa analisar a eficiência da estimativa realizada. Uma das formas de checar esta eficiência é através do coeficiente correlação (@), que expressa de 0 a 1 o nível de semelhança entre os valores calculados ( $\left.\mathrm{V}^{\prime}\right)$ e os valores reais $(\mathrm{V})$, conforme a Figura 3.

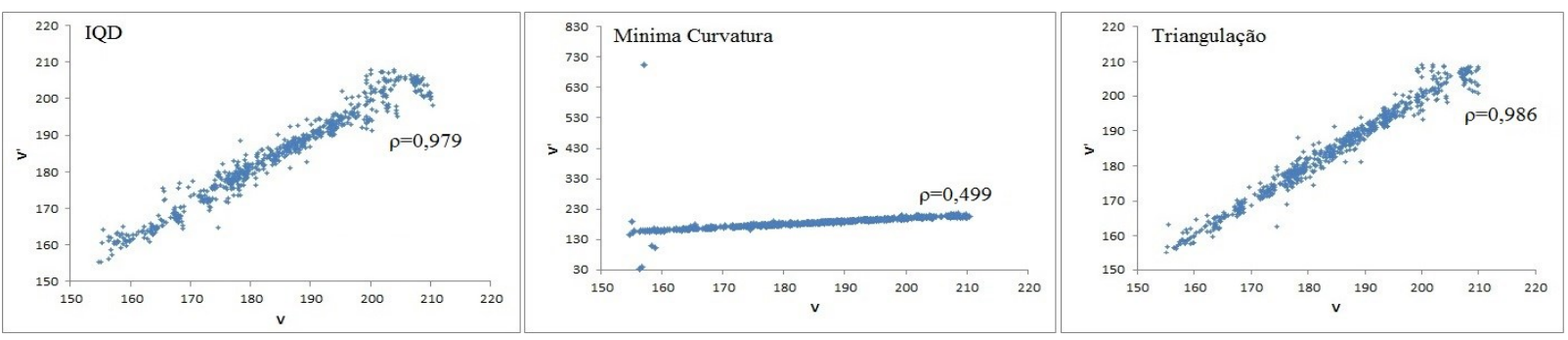

Figura 3: Analise do coeficiente de correlação. 
Conforme mostrado na figura acima a triangulação e o IQD obtiveram valores altos e bastante parecidos de @: 0,986 e 0,979, respectivamente, enquanto mínima curvatura mostrou-se ineficiente com $Q=0,499$, esse baixo valor se deve ao interpolador trabalhar com modelos de tendência, o que fez com que nas bordas do modelo fossem estimados valores extremos, como se pode ver no gráfico da Figura 3. O método escolhido foi a triangulação, pois o modelo de superfície gerado pelo método do IQD gerou uma superfície incompatível com a realidade observada na pilha.

Vale ressaltar que na estimativa do modelo de superfície não foram adotadas break lines, que são linhas de crista e pé de cada uma das bancadas, isso fez com que a superfície ficasse suavizada. Essa postura foi adotada em função de durante a geração do banco de dados não se ter feito essa discriminação de ponto de crista, ponto de pé.

A construção dos perfis topográficos da área, incluindo o cálculo dos ângulos de bermas, de taludes e o ângulo geral das faces foi realizada no AutoCad ${ }^{\circledR}$. Os equipamentos utilizados na determinação do ângulo de deposição natural do estéril foram a bússola geológica e régua de madeira.

Para a análise numérica da estabilidade dos taludes foi utilizado o programa SLOPE/W. O programa SLOPE/W é um software que utiliza a teoria do equilíbrio limite para calcular o fator de segurança (FS) de taludes em solos, rochas, entre outros. Este programa permite modelar diferentes tipos de materiais, estratigrafias e geometrias complexas de superfície de escoramento, taludes de aterros, barragens, rodovias, condições de pressão neutra e variáveis, utilizando uma grande variedade de modelos de materiais e suas características físicas.

A metodologia de análise de estabilidade utilizada foi o método proposto por Bishop \& Morgenstern (1960), ficando conhecido como método de Bishop simplificado, calculado pelas equações 1 e 2.

$$
F S=\frac{1}{\sum W \operatorname{sen} \alpha} \sum\left[c^{\prime} b+(W-u b) \operatorname{tg} \phi^{\prime}\right] / m_{\alpha}
$$

Sendo:

$$
m_{\alpha}=\cos \alpha\left[1+\frac{\operatorname{tg} \alpha \cdot \operatorname{tg} \phi^{\prime}}{F S_{i}}\right]
$$

Onde:

$c^{\prime}$ é a coesão do material;

$\varphi$ é o ângulo de atrito interno;

W é o peso da fatia;

$b$ é a largura da fatia;

$\alpha$ é o ângulo de inclinação da base da fatia e

$u$ é a pressão intersticial média na base da fatia.

A solução resulta num processo iterativo, onde se arbitra um valor para $\mathrm{FS}_{\mathrm{i}}$, na equação (2) e calcula-se o FS (1), o processo repete-se até que os valores de FS e FSi sejam iguais.

A avaliação dos impactos ambientais foi baseada nos métodos da "Matriz de Leopold", citada por Sanchez (2008), que consiste no levantamento dos aspectos e impactos ambientais que são listados em uma tabela e pontuados de acordo com sua relevância. Entretanto, o processo sugerido originalmente quantificava os impactos numa escala de 1 a 3, o que tornava a atribuição de valores muito restrita, fazendo, muitas vezes, com que impactos de relevância distinta tivessem que ser classificados igualmente.

A Dagoberto Barcellos S/A está em processo de implantação da ISO-14.001, tendo estabelecido uma série de medidas de avaliação ambiental, dentre estas, cita-se a metodologia mais detalhada que está sendo utilizada para avaliação dos impactos ambientais, através de uma escala mais ampla, que vai de 1 a 6, conforme a Tabela 1, e que foi adotada no presente trabalho. 
Tabela 1: Descrição da escala de fatores considerados na aia e seus parâmetros de classificação.

\begin{tabular}{|c|c|c|c|c|}
\hline \multirow[t]{2}{*}{ Pontuação } & $\begin{array}{c}\text { Frequência } \\
\text { (F) }\end{array}$ & $\begin{array}{c}\text { Abrangência/Vizinhança } \\
(\mathrm{V})\end{array}$ & Gravidade (G) & \multirow{2}{*}{$\begin{array}{c}\text { Controle ( C ) } \\
\text { Situação }\end{array}$} \\
\hline & \multicolumn{3}{|c|}{\begin{tabular}{|c|} 
Ocorrência \\
\end{tabular}} & \\
\hline 1 & $\geq 2$ anos & Sem reclamação & $\begin{array}{l}\text { Evento pouco } \\
\text { perceptível e } \\
\text { reversível por uma } \\
\text { ação imediata e } \\
\text { simples. }\end{array}$ & Controle total \\
\hline 2 & Anual & Anual & \begin{tabular}{|} 
Baixa, apresenta \\
prejuízo \\
moderado ao meio \\
ambiente (MA), \\
porém reversível \\
com ação \\
concomitante a \\
operação. \\
\end{tabular} & $\begin{array}{l}\text { Controle eficiente, } \\
20 \% \text { dos resultados } \\
\text { do monitoramento } \\
\text { não correspondem } \\
\text { aos índices } \\
\text { previstos nas } \\
\text { normas internas e } \\
\text { na legislação. } \\
\end{array}$ \\
\hline 3 & Semestral & Semestral & $\begin{array}{c}\text { Média, evento } \\
\text { causa prejuízo } \\
\text { moderado ao meio } \\
\text { ambiente (MA), } \\
\text { porém reversível } \\
\text { com ação } \\
\text { concomitante a } \\
\text { operação. }\end{array}$ & $\begin{array}{l}\text { Média eficiência, } \\
40 \% \text { dos resultados } \\
\text { do monitoramento } \\
\text { não correspondem } \\
\text { aos índices previstos } \\
\text { nas normas internas } \\
\text { e na legislação. }\end{array}$ \\
\hline 4 & Trimestral & Trimestral & $\begin{array}{l}\text { Grande, evento } \\
\text { causa prejuízos ao } \\
\text { MA, requer ação } \\
\text { complexa antes e } \\
\text { após a operação. }\end{array}$ & $\begin{array}{c}\text { Com baixa } \\
\text { eficiência, com } \\
\text { ineficiência no } \\
\text { monitoramento } \\
\text { previsto nas normas } \\
\text { internas e na } \\
\text { legislação. }\end{array}$ \\
\hline 5 & Mensal & Mensal & $\begin{array}{c}\text { Irreversível } \\
\text { temporariamente. } \\
\leq 4 \text { anos }\end{array}$ & $\begin{array}{c}\text { Péssima eficiência } \\
\text { atende parte das } \\
\text { normas internas e } \\
\text { legislação, sem } \\
\text { monitoramento. }\end{array}$ \\
\hline 6 & Diário & Diário & $\begin{array}{c}\text { Irreversível } \\
\text { temporariamente. } \\
>4 \text { anos }\end{array}$ & $\begin{array}{l}\text { Sem controle, sem } \\
\text { monitoramento e } \\
\text { não atende as } \\
\text { normas internas e } \\
\text { legislação. }\end{array}$ \\
\hline
\end{tabular}

Após a quantificação de cada um dos impactos, faz-se o somatório destes valores, conforme a equação (3). 
Onde os índices F, V, G e C, correspondem à Tabela 1.

A partir do somatório, obtido com a equação (1), classificam-se os impactos de acordo com sua relevância (

Tabela 2).

Tabela 2: Classificação dos impactos.

\begin{tabular}{c|c|c} 
Classificação de Impacto & Pontuação & Significância \\
\hline Impacto pequeno & Entre 0 e 8 & Não \\
\hline Impacto médio & Entre 9 e 15 & Sim \\
\hline Impacto grave & Acima de 15 & Sim
\end{tabular}

As medidas mitigadoras propostas no plano de ação foram feitas de acordo com o conhecimento da área e referências de Sanchez (2008). A construção dos planos de ação e monitoramento fez-se baseada nos resultados classificados na mesma tabela, hierarquizados de acordo com os resultados do somatório da equação 1 .

\section{Resultados e análises}

\subsection{Geometria da pilha}

A partir do processamento dos dados topográficos, obteve-se o mapa planialtimétrico da pilha (Figura 4), onde são apresentadas suas características geométricas, volume e áreas. 


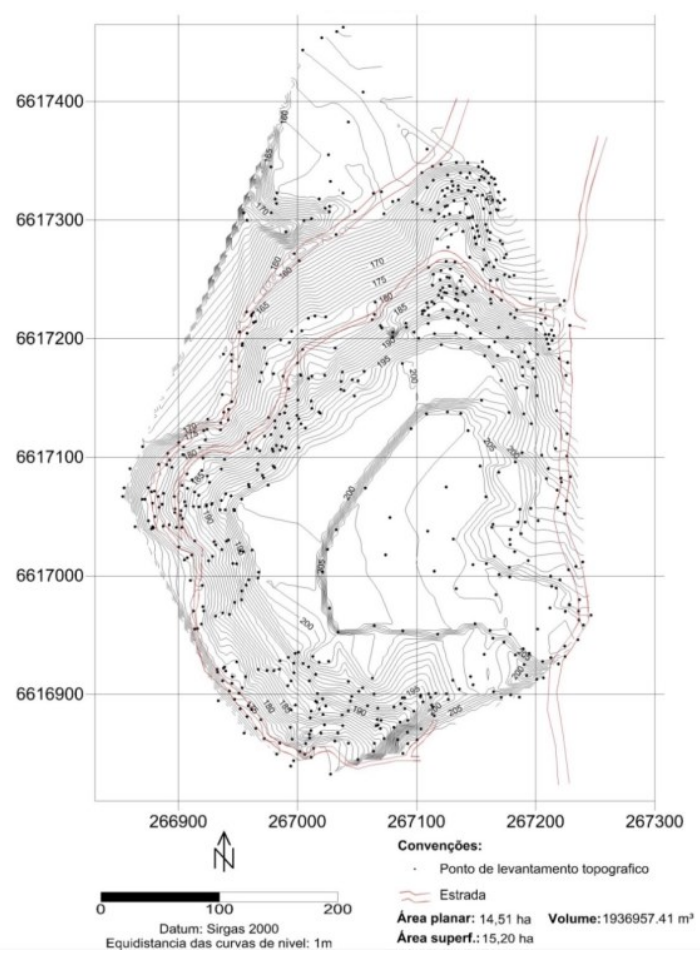

Figura 4: Mapa topográfico planialtimétrico da pilha R8.

Os ângulos de taludes e bermas, analisados através de perfis topográficos, que ilustram a geometria individual de cada uma das bancadas e a geometria geral dos taludes em relação à horizontal, podem ser vistos na Figura 5. Cada um destes perfis foi locado buscando a melhor forma de interceptar o mais ortogonalmente possível as duas faces opostas abrangidas. 


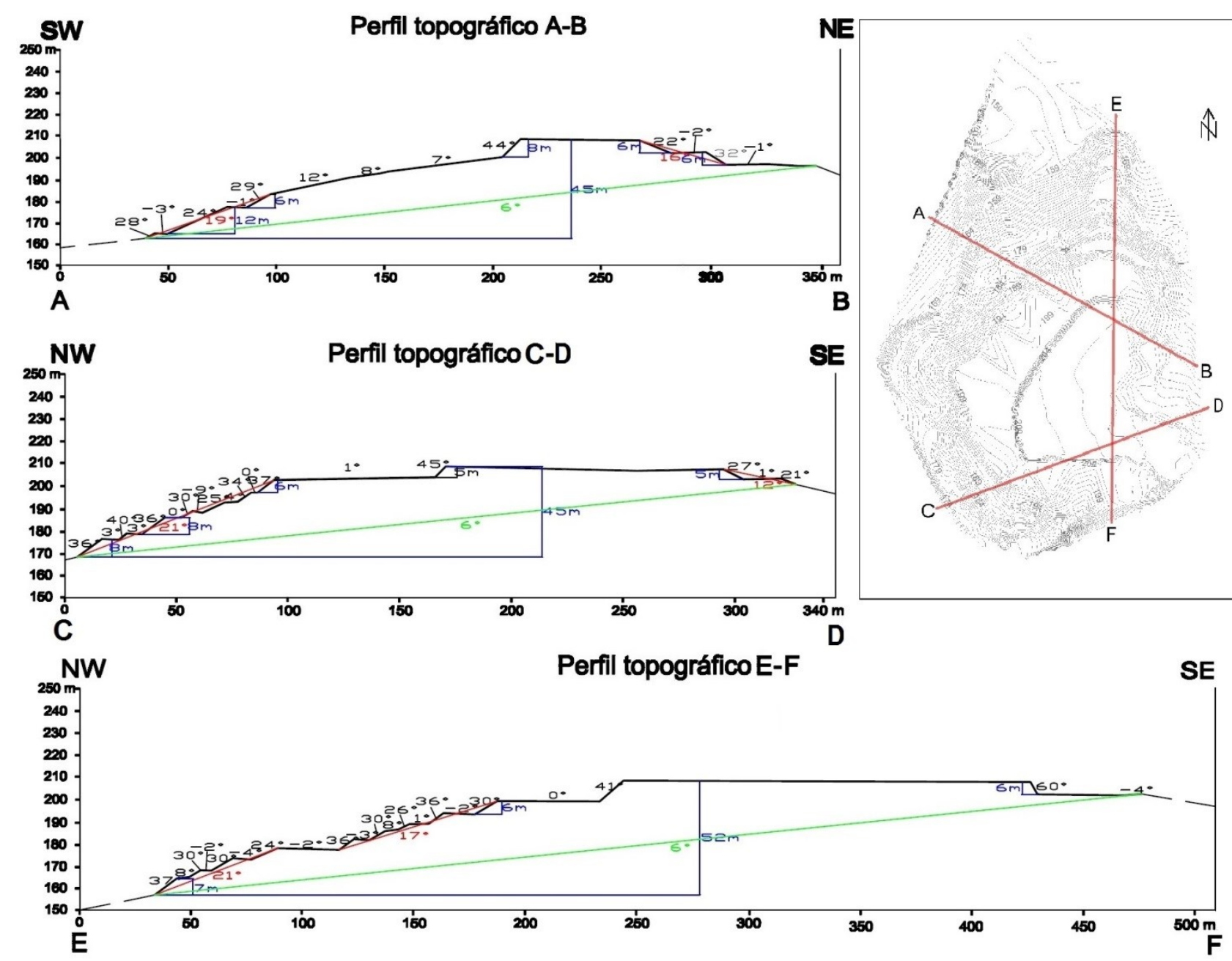

Figura 5: Localização e perfis topográficos da pilha. Em azul: medidas de altura; em vermelho: ângulos gerais; em preto: ângulos de talude e em verde: ângulo do terreno.

\subsection{Estabilidade}

O estéril que compõe a pilha é muito heterogêneo, granulometricamente variando desde areia até matacos, entretanto, segundo Bates (2002), esta é uma característica inerente deste tipo de construção, pois é natural que haja uma menor atenção quanto aos processos de controle granulométrico nos desmontes de decapeamento.

A ABNT NBR - 13.029, que regula a construção de pilhas de estéril, foi publicada em 1993 e atualizada em 2006, sofrendo modificações na forma de abordagem das especificações construtivas, pois enquanto a primeira versão trazia recomendações especificas de ângulos de bermas, taludes e terreno de fundação, a versão atualizada recomenda apenas fatores de segurança. Porém, considera-se que a versão de 1993 apresenta importantes recomendações quanto às "boas práticas" aplicadas à pilha de estéril.

A heterogeneidade é um complicador no que diz respeito à determinação de propriedades como coesão e ângulo de atrito interno, dados indispensáveis ao cálculo do FS, que são fornecidos por tabelas de referência tradicionais somente para materiais de granulometrias específicas. Contudo, o trabalho publicado por Zhou et al. (2013), dispôs diversos valores para coesão e atrito interno de misturas de materiais em construções hídricas na China. Daí, adotaram-se os menores valores citados, tendo em vista uma margem de segurança na estimativa, sendo a coesão de $10 \mathrm{Kpa}$ e o ângulo de atrito interno de $25^{\circ}$. O peso específico utilizado foi informado pela empresa, sendo de aproximadamente $19 \mathrm{KN} / \mathrm{m}^{2}$. 
Como a determinação do FS para cada uma das bancadas da pilha individualmente seria um cálculo exaustivo, de modo a se ter um panorama geral da situação da mesma, calculou-se o fator de segurança, utilizando os dados acima, para as médias dos ângulos de inclinação dos taludes e as médias de altura de cada perfil, considerando que cada um destes pares representasse um "talude médio", conforme a Tabela 3. Os ângulos gerais de talude apresentaram altos fatores de segurança (acima de 7).

Tabela 3: Fatores de segurança para os "taludes médios".

\begin{tabular}{c|c|c|c} 
Perfil & Altura Média & Ângulo médio & FS \\
\hline A-B & $7,6 \mathrm{~m}$ & $27,3^{\circ}$ & 1,762 \\
\hline C-D & $5,0 \mathrm{~m}$ & $32,8^{\circ}$ & 2,007 \\
\hline E-F & $5,3 \mathrm{~m}$ & $34,5^{\circ}$ & 1,743
\end{tabular}

Também, para que se tivesse uma ideia de estabilidade na pior situação encontrada na pilha, se fez o cálculo do fator se segurança para o talude do perfil E-F, apresentado na Figura 5, que possui o maior ângulo de inclinação: $60^{\circ}$ e este apresentou FS de 1,28, inferior ao estipulado de 1,5.

A heterogeneidade também prejudica a determinação do ângulo natural de deposição, pois cada tipo de material, com suas características intrínsecas somadas às grandes diferenças granulométricas, comporta-se de forma distinta. Como não há tabelas ou ábacos que se apliquem à inferência de ângulos neste tipo de mistura de materiais, optou-se por determinar o ângulo em questão através da média aritmética de 16 amostras de ângulos de deposição medidos em campo.

Considerando que os valores estimados em tabelas para outros tipos de materiais sempre são dados em faixas de valores de até $15^{\circ}$, esse intervalo é um aceitável. Como as boas práticas adotadas determinam que o ângulo dos taludes da pilha seja inferior ao ângulo de deposição natural, considerou-se $36^{\circ}$ como ângulo máximo para os taludes, valor inferior à média dos ângulos encontrados, que é de $36,5^{\circ}$.

Os ângulos foram medidos no material estéril que chega do decapeamento e que, após ser descarregado pelos caminhões, forma pequenas pilhas com cerca 1,5 m de altura. Nestas pequenas pilhas, antes que fossem espalhadas e compactadas pelo trator de esteiras, mediu-se o ângulo de estabilização, que conforme o esperado variou com a granulometria, medindo de $31^{\circ} \mathrm{em}$ materiais finos até $45^{\circ} \mathrm{em}$ matérias grossos.

Na Figura 5, o ângulo médio dos taludes da pilha é de cerca de $30^{\circ}$, e os ângulos gerais de taludes nunca ultrapassam esse valor, entretanto, há zonas da pilha em que o ângulo de talude chega a até $60^{\circ}$, estando $40 \%$ cima do ângulo adequado.

A altura de taludes recomendada é de $10 \mathrm{~m}$, já a altura máxima encontrada na pilha é de $12 \mathrm{~m}$. Levando em conta a granulometria irregular do material é tolerável que hajam variações nestes valores e, vale ressaltar que a média da altura dos taludes esta em torno de $6 \mathrm{~m}$. Já no que diz respeito à largura de bermas o recomendado são $6 \mathrm{~m}$, no mínimo, porém, na pilha predominam larguras inferiores a este valor (Figura 5). A média das larguras é de $10 \mathrm{~m}$, entretanto, este valor é influenciado pela berma do penúltimo banco que mede mais de $60 \mathrm{~m}$, o que contribui para uma situação de maior estabilidade.

Na Figura 6, com base nos dados do levantamento topográfico, apresenta-se um mapa de risco da pilha, representando as zonas com ângulos de taludes e bermas acima dos especificados, respectivamente, $36^{\circ}$ e $-1^{\circ}$ em direção ao pé do talude sobrejacente. 


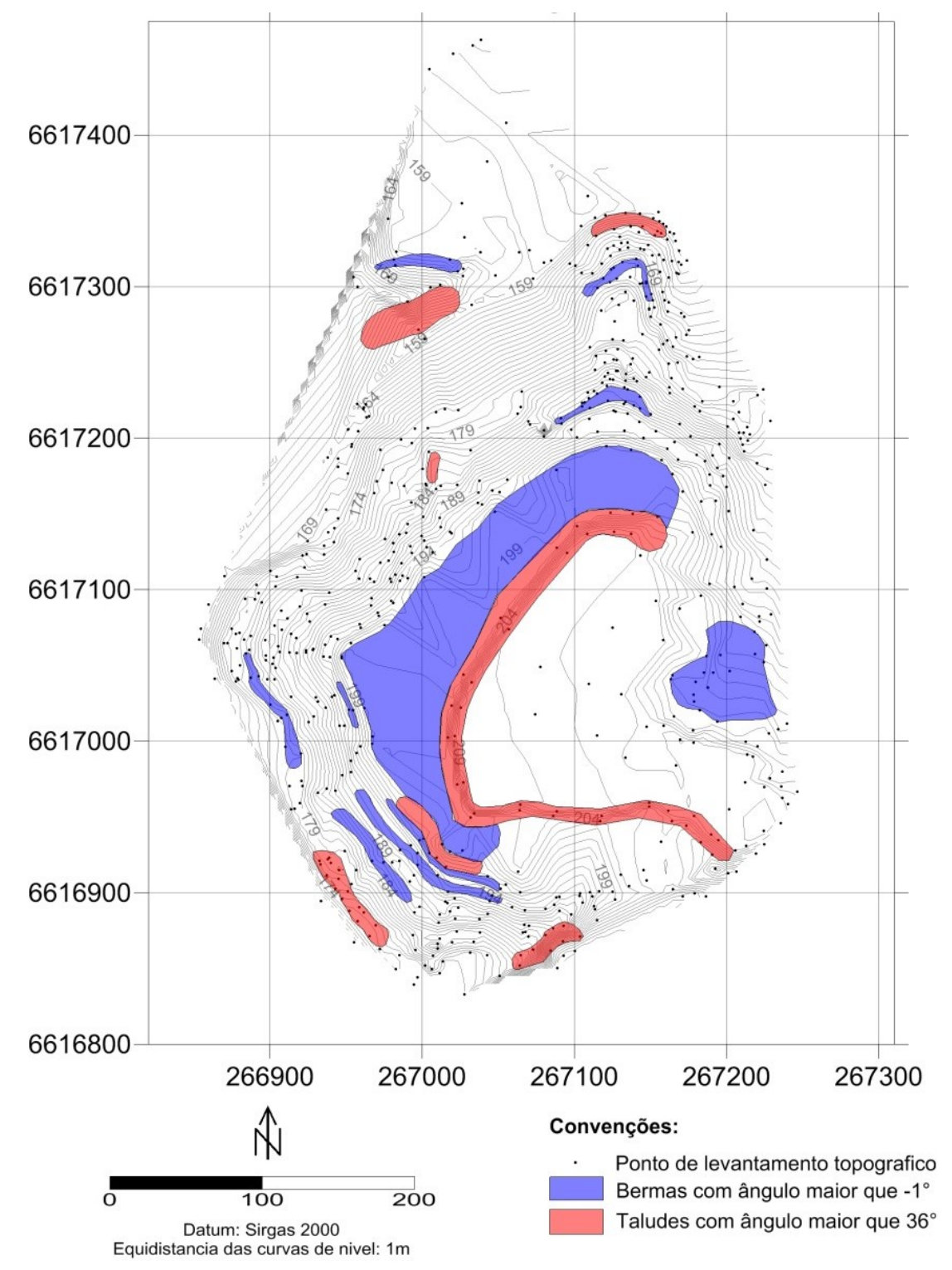

Figura 6: Mapa de risco da pilha com relação aos ângulos de taludes e bermas.

A título de comparação, considerando-se a altura máxima de $10 \mathrm{~m}$ recomendada pelas boas práticas, se estimou qual seria o ângulo máximo de talude para que, nestas condições, se atendesse o FS de 1,5. O valor obtido foi de $30^{\circ}$, inferior ao ângulo recomendado em relação ao ângulo de repouso natural. Porém, como todo este cálculo de FS está baseado em dados oriundos de estimativas baseadas no trabalho de Zhou et al. (2013) e há uma grande variação na altura dos taludes da pilha, o que influencia diretamente no valor do FS, se optou por conservar os $36^{\circ}$ calculados a partir de dados reais, como ângulo recomendado.

O terreno onde foi construída a pilha não foi mapeado antes da construção da mesma, portanto, não se tem dados de sua inclinação. A alternativa foi estimá-lo através do mostrado na Figura 5, apresentada anteriormente, chegando-se a um valor médio de $6^{\circ}$, muito inferior ao máximo estipulado: $18^{\circ}$. Observando-se a mesma figura, nota-se que não há bermas na crista dos taludes.

A altura do nível de água na pilha é um fator presente nas bibliografias consultadas (Petronilho, 2010; Maciel Filho, 2008; et al.), sendo este um importante indicador de instabilidade. Na pilha R8, não há piezômetros instalados que possibilitem a medição deste nível, porém, não são encontradas surgências nos taludes ou bermas superiores que indiquem significativa elevação do nível de água. 
Essa constatação é salientada por Maciel Filho (2008), que cita que pilhas compostas de materiais não argilosos costumam ter altas porosidades, não apresentando, portanto, potencial de retenção de água.

\section{Avaliação de impacto ambiental (AIA)}

A Tabela 4 traz a relação dos aspectos e impactos ambientais referentes à atividade de disposição de estéril na pilha R8 e sua hierarquização, de acordo com os parâmetros estabelecidos e descritos nos materiais e métodos.

Tabela 4: Matriz de AIA da pilha R8.

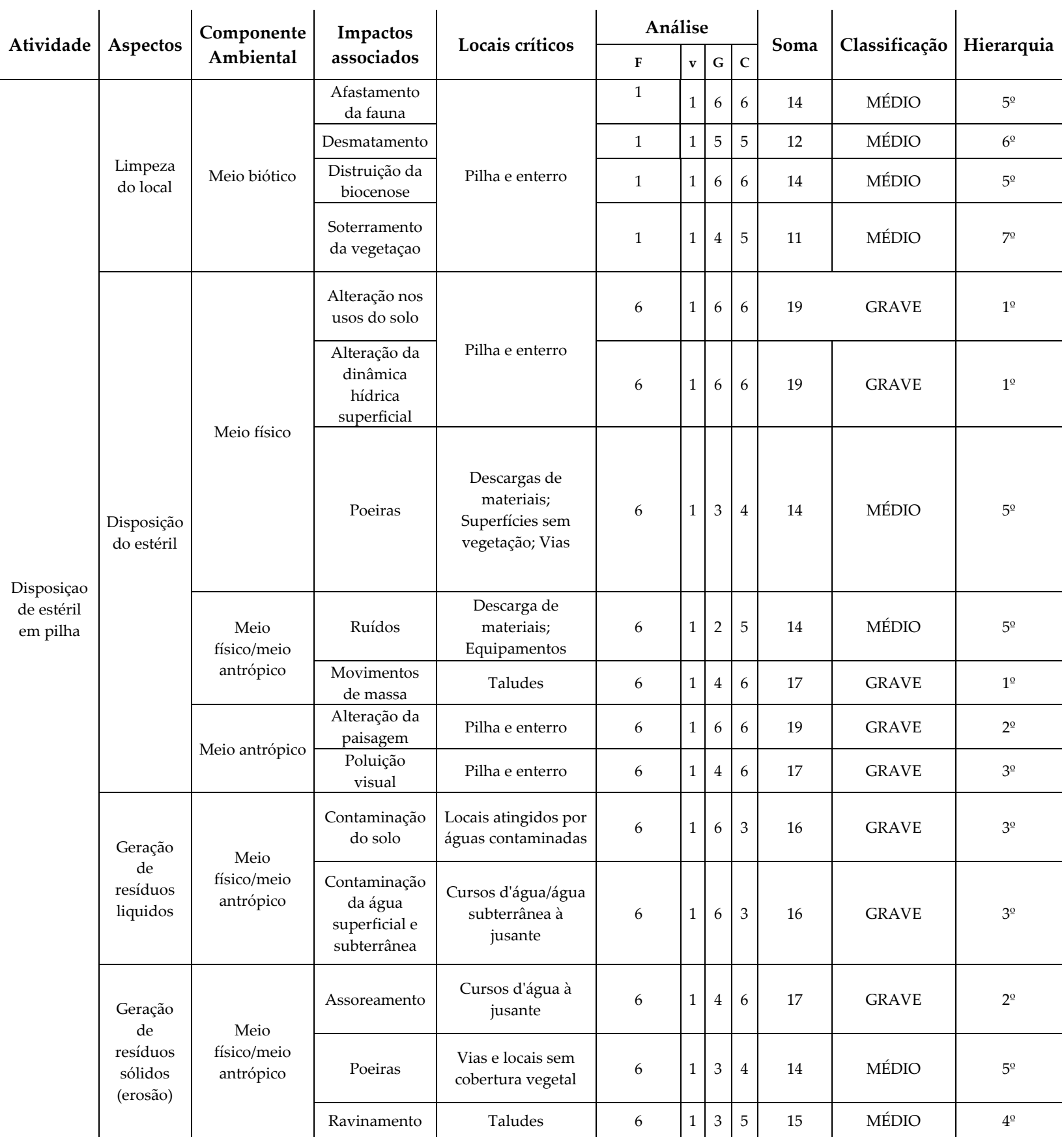


Nota-se que $50 \%$ dos impactos levantados são graves e 50\% são médios, sendo que nenhum dos impactos teve pontuação inferior a 11 pontos, acima dos 8 estipulados como máximo para que o impacto fosse considerado pequeno. Isto se deve em grande parte, à falta de controle observada em quase todas as análises e demonstra que a pilha apresenta uma matriz de impacto com importante nível negativo, pois todos os impactos são significativos.

Medidas mitigadoras e compensatórias

As medidas mitigadoras e compensatórias propostas para cada impacto são apresentadas no plano de ação representado na Tabela 5, de acordo com a hierarquização mostrada no quadro anterior. Entretanto, como havia vários impactos com as mesmas pontuações, acrescentou-se uma coluna dada como critério de desempate, reordenando qualitativamente cada impacto, quanto ao grau de risco que este representa ao meio antrópico, ou que envolvem riscos de acidentes.

Tabela 5: Plano de ação

\begin{tabular}{|c|c|c|c|c|}
\hline \multirow{2}{*}{ Hierarquia } & \multirow{2}{*}{ Clas. De risco } & \multirow{2}{*}{ Impactos } & \multicolumn{2}{|l|}{ Medidas } \\
\hline & & & Mitigadoras & Compensatórias \\
\hline \multirow{3}{*}{$1^{\circ}$} & 1 & Alteração no uso do solo & Programas de conscientização & Reflorestamento \\
\hline & 2 & $\begin{array}{c}\text { Alteração da dinâmica } \\
\text { hìdrica }\end{array}$ & Adequação das drenagens & Reflorestamento \\
\hline & 3 & Alteração da paisagem & Cortina vegetal; revegetação & - \\
\hline \multirow{3}{*}{$2^{\circ}$} & 1 & Movimentos de massa & $\begin{array}{l}\text { Revegetação, correção do ângulo de } \\
\text { taludes, adequação das drenagens }\end{array}$ & - \\
\hline & 2 & Assoreamento & Bacias de sedimentação & - \\
\hline & 3 & Poluição visual & Cortina vegetal; revegetação & - \\
\hline $3^{\mathrm{o}}$ & 1 & $\begin{array}{l}\text { Contaminação da água } \\
\text { superficial e subterrânea }\end{array}$ & Bacias de sedimentação & - \\
\hline $3^{\mathrm{o}}$ & 2 & Contaminação do solo & Remediação, bacias de sedimentação & - \\
\hline $4^{\circ}$ & - & Ravinamento & Construção de leiras; revetação & - \\
\hline \multirow{4}{*}{$5^{\mathrm{o}}$} & 1 & Poeiras & $\begin{array}{c}\text { Umidificação das vias; revegetação de } \\
\text { áreas de solo/estéril exposto; cortina } \\
\text { vegetal }\end{array}$ & - \\
\hline & 2 & Ruídos & $\begin{array}{l}\text { Uso de EPI; manutenção correta de } \\
\text { equipamentos; cortina vegetal }\end{array}$ & - \\
\hline & 3 & Afastamento da fauna & Revegetação & $\begin{array}{l}\text { Manutenção de áreas } \\
\text { de conservação; } \\
\text { reflorestamento }\end{array}$ \\
\hline & 4 & Destruição da biocenose & $\begin{array}{c}\text { Revegetação, estruturas para travessia } \\
\text { de animais }\end{array}$ & $\begin{array}{l}\text { Manutenção de áreas } \\
\text { de conservação; } \\
\text { reflorestamento } \\
\end{array}$ \\
\hline $6^{\circ}$ & - & Desmatamento & Minimização da supressão & Reflorestamento \\
\hline $7^{o}$ & - & Soterramento de vegetação & Minimização da supressão & Reflorestamento \\
\hline
\end{tabular}


Das medidas mitigadoras e compensatórias propostas, a minimização da supressão durante a execução da pilha não mais é possível, pois a disposição já está nos estágios finais. Entretanto, há medidas já implantadas, que contribuem de forma expressiva na atenuação, principalmente, do dos impactos da hierarquia $5^{\circ}$ e $6^{\circ}$, tais como:

- manutenção de uma reserva de preservação de cerca de 200 ha de mata nativa;

- parte significativa da pilha já está revegetada;

- plantio de espécies exóticas (eucalipto) e nativas no entorno da pilha;

- programa de monitoramento das águas superficiais;

- umidificação das vias periodicamente;

- manutenção dos equipamentos e o uso de EPIs;

- existem trabalhos de conscientização à comunidade.

Para as medidas ainda não implantadas, seguindo a hierarquia apresentada no plano de ação mostrado anteriormente, é proposto o cronograma de execução apresentado na Tabela 6. Vale ressaltar que há, operacionalmente, medidas afins entre si, isto explica o fato de medidas listadas em hierarquia inferior estarem com período de execução concomitante às medidas em classificação superior. Para a construção das bacias de sedimentação e piezômetros, no mapa de vetores representado na Figura 7, são as plotadas localizações propostas.

Tabela 6: Cronograma de implantação das medidas mitigadoras e compensatórias

\begin{tabular}{|c|c|c|c|c|c|c|c|}
\hline \multirow{2}{*}{ Medidas mitagadoras } & \multirow{2}{*}{ Implantada } & \multicolumn{2}{|c|}{$1^{0}$ ano } & \multicolumn{2}{|c|}{$2^{o}$ ano } & \multicolumn{2}{|c|}{$3^{0}$ ano } \\
\hline & & $1^{\circ}$ sem. & $2 \sim$ sem. & $1^{\circ} \mathrm{sem}$. & $2^{\circ} \mathrm{sem}$. & $1^{\circ} \mathrm{sem}$. & $2^{\circ}$ sem. \\
\hline Programas de conscientizaçao & $\operatorname{sim}$ & - & - & - & - & - & - \\
\hline Adequação das drenagens & não & $x$ & $x$ & - & - & - & - \\
\hline Cortina vegetal & $\operatorname{sim}$ & - & & - & - & - & - \\
\hline Revegetação & em parte & - & $x$ & $x$ & $x$ & - & - \\
\hline Correção do ângulo de taludes & não & - & $x$ & - & - & - & - \\
\hline Levantamentos topográficos & em parte & - & & - & - & $x$ & - \\
\hline Bacias de sedimentação & em parte & - & $x$ & - & - & - & - \\
\hline Remediação de solos & não & $x$ & & - & - & - & - \\
\hline Construção de leiras & não & - & $x$ & - & - & - & - \\
\hline Umidificação das vias & $\operatorname{sim}$ & - & & - & - & - & - \\
\hline $\begin{array}{c}\text { EPIs, manutenção correta de } \\
\text { equipamentos }\end{array}$ & $\operatorname{sim}$ & - & & - & - & - & - \\
\hline
\end{tabular}




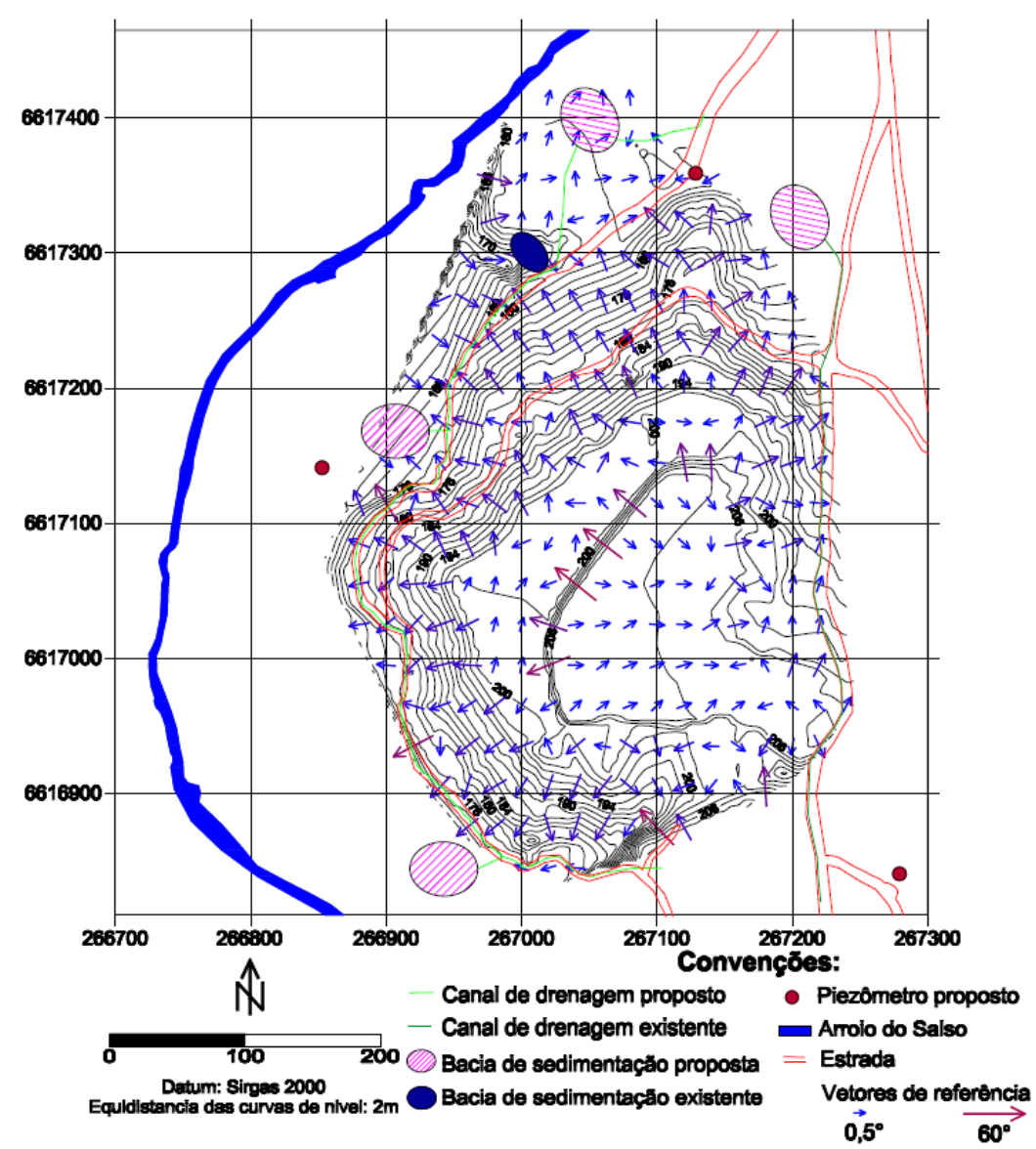

Figura 7: Mapa de vetores com direções de escoamento e fluxo das águas superficiais e localização dos piezômetros e bacias de sedimentação propostos.

Conforme se pode visualizar no mapa apresentado na Figura 7 há na área apenas uma bacia de decantação que está completamente assoreada e, visualizando a direção preferencial do fluxo de águas em seu entorno, esta deixaria de reter uma importante parcela de sedimentos gerados a seu norte, onde é proposta a construção de uma nova bacia. Na porção centro-oeste da pilha nota-se uma direção de fluxo oeste, na metade sul um fluxo sudoeste e na metade leste da pilha a direção de drenagem é, preferencialmente, leste. Nenhum destes fluxos de drenagem é direcionado a qualquer tipo de sistema de contensão de sólidos.

Conforme pode ser visto na Figura 7, são propostas bacias de decantação a cada um destes fluxos principais, de modo a evitar o assoreamento das drenagens. Também se propõe uma quantidade mínima de três piezômetros, sendo um a montante e dois à jusante, para que se possam ter dados de nível freático e qualidade da água subterrânea.

\section{Monitoramento}

O plano de monitoramento, para Sánchez (2008), pode ser dividido em pré-operacional, operacional e pós-operacional. Como a pilha de estéril está em fase de conclusão, o plano apresentado na Tabela 7 se classifica como operacional e pós-operacional, apresentando parâmetros a serem monitorados e a periodicidade das amostragens para um período de 10 anos, conforme recomendações constantes nos termos de referência para estudos ambientais dos órgãos de controle (Fepam, IBAMA e CONAMA). Vale ressaltar que parâmetros sociais também integram este monitoramento, sendo realizados durante reuniões previstas nos programas de conscientização. 
Tabela 7: Plano de monitoramento, onde a amostragem é diária (D), mensal (M), trimestral (T), semestral (S) e anual (A).

\begin{tabular}{c|c|c|c|c|c|c|c|c|c|c} 
Parâmetros & $\begin{array}{c}\mathbf{1}^{\mathbf{0}} \\
\text { ano }\end{array}$ & $\begin{array}{c}\mathbf{2}^{\mathbf{0}} \\
\text { ano }\end{array}$ & $\begin{array}{c}\mathbf{3}^{\mathbf{0}} \\
\text { ano }\end{array}$ & $\begin{array}{c}\mathbf{4}^{\mathbf{0}} \\
\text { ano }\end{array}$ & $\begin{array}{c}\mathbf{5}^{\mathbf{0}} \\
\text { ano }\end{array}$ & $\begin{array}{c}\mathbf{6}^{\mathbf{0}} \\
\text { ano }\end{array}$ & $\begin{array}{c}\mathbf{7}^{\mathbf{0}} \\
\text { ano }\end{array}$ & $\begin{array}{c}\mathbf{8}^{\mathbf{o}} \\
\text { ano }\end{array}$ & $\begin{array}{c}\mathbf{9}^{\mathbf{o}} \\
\text { ano }\end{array}$ & $\begin{array}{c}\mathbf{1 0}^{\mathbf{o}} \\
\text { ano }\end{array}$ \\
\hline Programas de conscientizaça & $\mathrm{A}$ & $\mathrm{A}$ & $\mathrm{A}$ & $\mathrm{A}$ & $\mathrm{A}$ & $\mathrm{A}$ & $\mathrm{A}$ & $\mathrm{A}$ & $\mathrm{A}$ & $\mathrm{A}$ \\
\hline $\begin{array}{c}\text { Qualidade de águas } \\
\text { superficiais }\end{array}$ & $\mathrm{S}$ & $\mathrm{S}$ & $\mathrm{S}$ & $\mathrm{S}$ & $\mathrm{S}$ & $\mathrm{S}$ & $\mathrm{S}$ & $\mathrm{S}$ & $\mathrm{S}$ & $\mathrm{S}$ \\
\hline Assoreamento & $\mathrm{A}$ & $\mathrm{A}$ & $\mathrm{A}$ & $\mathrm{A}$ & $\mathrm{A}$ & $\mathrm{A}$ & $\mathrm{A}$ & $\mathrm{A}$ & $\mathrm{A}$ & $\mathrm{A}$ \\
\hline Contaminação do solo & $\mathrm{A}$ & $\mathrm{A}$ & $\mathrm{A}$ & $\mathrm{A}$ & $\mathrm{A}$ & $\mathrm{A}$ & $\mathrm{A}$ & $\mathrm{A}$ & $\mathrm{A}$ & $\mathrm{A}$ \\
\hline $\begin{array}{c}\text { Bacias de sed. E sist. De } \\
\text { drenagem }\end{array}$ & $\mathrm{T}$ & $\mathrm{T}$ & $\mathrm{T}$ & $\mathrm{T}$ & $\mathrm{T}$ & $\mathrm{T}$ & $\mathrm{T}$ & $\mathrm{T}$ & $\mathrm{T}$ & $\mathrm{T}$ \\
\hline $\begin{array}{c}\text { Geometria/estabilidade } \\
\text { (marcos superficiais) }\end{array}$ & $\mathrm{S}$ & $\mathrm{S}$ & $\mathrm{S}$ & $\mathrm{S}$ & $\mathrm{S}$ & $\mathrm{S}$ & $\mathrm{S}$ & $\mathrm{S}$ & $\mathrm{S}$ & $\mathrm{S}$ \\
\hline Umidificação & $\mathrm{D}$ & $\mathrm{D}$ & $\mathrm{D}$ & $\mathrm{D}$ & $\mathrm{D}$ & $\mathrm{D}$ & $\mathrm{D}$ & $\mathrm{D}$ & $\mathrm{D}$ & $\mathrm{D}$ \\
\hline Cortinas vegetais & $\mathrm{S}$ & $\mathrm{S}$ & $\mathrm{S}$ & $\mathrm{S}$ & $\mathrm{S}$ & $\mathrm{S}$ & $\mathrm{S}$ & $\mathrm{S}$ & $\mathrm{S}$ & $\mathrm{S}$ \\
\hline Vias & $\mathrm{M}$ & $\mathrm{M}$ & $\mathrm{M}$ & $\mathrm{M}$ & $\mathrm{M}$ & $\mathrm{M}$ & $\mathrm{M}$ & $\mathrm{M}$ & $\mathrm{M}$ & $\mathrm{M}$ \\
\hline Revegetação & $\mathrm{M}$ & $\mathrm{M}$ & $\mathrm{M}$ & $\mathrm{M}$ & $\mathrm{M}$ & $\mathrm{M}$ & $\mathrm{M}$ & $\mathrm{M}$ & $\mathrm{M}$ & $\mathrm{M}$ \\
\hline Espécies/habitats & $\mathrm{A}$ & $\mathrm{A}$ & $\mathrm{A}$ & $\mathrm{A}$ & $\mathrm{A}$ & $\mathrm{A}$ & $\mathrm{A}$ & $\mathrm{A}$ & $\mathrm{A}$ & $\mathrm{A}$ \\
\hline Desmaamento & $\mathrm{A}$ & $\mathrm{A}$ & $\mathrm{A}$ & $\mathrm{A}$ & $\mathrm{A}$ & $\mathrm{A}$ & $\mathrm{A}$ & $\mathrm{A}$ & $\mathrm{A}$ & $\mathrm{A}$ \\
\hline Áreas de conservação & $\mathrm{A}$ & $\mathrm{A}$ & $\mathrm{A}$ & $\mathrm{A}$ & $\mathrm{A}$ & $\mathrm{A}$ & $\mathrm{A}$ & $\mathrm{A}$ & $\mathrm{A}$ & $\mathrm{A}$ \\
\hline Reflorestamento & $\mathrm{T}$ & $\mathrm{T}$ & $\mathrm{T}$ & $\mathrm{T}$ & $\mathrm{T}$ & $\mathrm{T}$ & $\mathrm{T}$ & $\mathrm{T}$ & $\mathrm{T}$ & $\mathrm{T}$ \\
\hline $\begin{array}{c}\text { Estudo de aval. } \\
\text { Espécies/habitats }\end{array}$ & $\mathrm{A}$ & - & - & - & $\mathrm{A}$ & - & - & - & $\mathrm{A}$ & -
\end{tabular}

Dos parâmetros a serem monitorados apresentados anteriormente, são mostradas na Figura 8 as análises de águas superficiais realizadas no período de 2004 a 2011. As águas amostradas são classificadas, de acordo com a Resolução 357-2005 do CONAMA, como doces de classe III e, conforme se pode visualizar, os valores estão dentro do especificado, mas é claro o aumento da concentração de sólidos à jusante, indicando que a pilha está exercendo influência nas águas por reflexo de problemas no controle dos impactos, como por exemplo, a inexistência de baias de sedimentação. Os parâmetros alcalinidade e condutividade, que também apresentam incremento à jusante, não são citados na resolução, mas são associáveis aos mesmos problemas, podendo estar sendo gerados pelo aumento da concentração de sólidos carbonáticos ou mesmo por íons metálicos provenientes de rochas mineralizadas. 


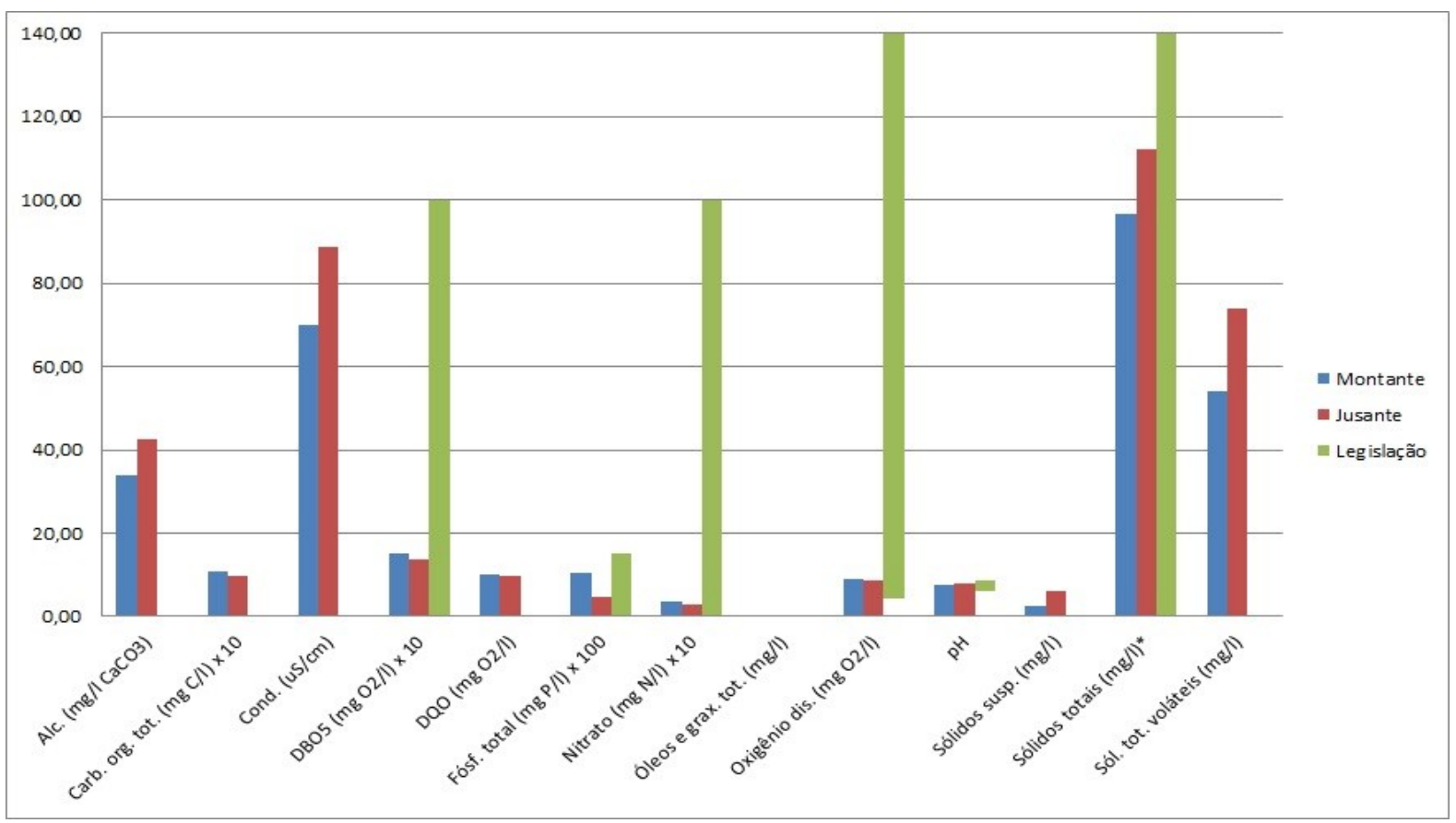

Figura 8: Gráfico dos valores médios das amostras anuais de água de 2004 a 2011. *O valor máximo para sólidos totais é de 500 mg/l.

\section{Conclusões e recomendações}

A geometria da pilha, segundo a normatização ABNT/NBR-13.029 de 1993 que foi adotada como boas práticas, está atendendo apenas de forma parcial as determinações, pois conforme o levantado anteriormente há zonas que não apresentam conformação adequada de bermas e taludes, a pilha não possui leiras nas cristas dos bancos e a revegetação e o sistema de drenagem são insuficientes. Entretanto, a estimativa de ângulo de inclinação do terreno, a medida de altura máxima da pilha, o sistema de execução (ascendente) e a manutenção das áreas de APP estão de acordo. Neste levantamento geométrico, como forma de uma estimativa mais precisa de volumes, seria interessante a adoção de break lines na estimativa do modelo de superfície.

No que diz respeito à normatização atualizada ABNT/NBR-13.029 de 2006, quanto à estabilidade são citados apenas fatores de segurança, e estes, segundo as estimativas através das médias da geometria dos taludes, estão conformes, tanto nos taludes intermediários quanto nos gerais. Vale ressaltar que os valores de coesão e ângulo de atrito foram estimados, conforme descrito na metodologia.

A AIA realizada revelou que uma boa parte das medidas mitigadoras e compensatórias já foi, ou está sendo implantada, mas também elucidou uma série de medidas que ainda devem ser postas em prática. Uma prova clara da ineficiência dos processos de atenuação dos impactos são os resultados dos monitoramentos de águas a montante e jusante, onde se pode notar um significativo aumento nos parâmetros influenciáveis pela atividade de disposição de estéril.

Outro ponto importante seria uma análise mais aprofundada do que está provocando o aumento da condutividade, tendo em vista que na pilha são encontradas amostras de rochas contendo metais, tais como sulfetos e óxidos de cobre.

O estudo de avaliação das espécies/habitats deve servir de base à decisão sobre a possibilidade/necessidade da construção das travessias para animais e à escolha das espécies vegetais mais adequadas a serem utilizadas tanto na revegetação quanto no reflorestamento. Uma recomendação seria a construção de bermas com o plantio do capim Vetiver, que, além de formar uma barreira às águas das chuvas que correm pelas faces dos taludes, tem potencial de aumentar substancialmente a estabilidade (Michele et al., 2010). Este potencial de aumento de estabilidade 
poderá ser considerado em posteriores análises in situ para determinação dos parâmetros reais de coesão e atrito interno, de forma a se poder ter uma estimativa mais segura e realista do ângulo ideal para os taludes, tendo em vista a representatividade que variações neste ângulo refletem nas áreas da pilha a serem corrigidas.

Recomenda-se o atendimento dos planos de ação e monitoramento propostos e a adoção de seus cronogramas como orientação à adequação da pilha às normas. $\mathrm{Na}$ instalação de piezômetros e marcos superficiais e do sistema de drenagem e retenção de sedimentos deve ser considerada a localização proposta. Como as bacias de sedimentação foram estimadas empiricamente, há a possibilidade de realização de monitoramento periódico do volume de sólidos recolhido nestas, para que se tenham valores que permitam um dimensionamento mais preciso.

Por fim, conclui-se que a pilha R8 atende somente em parte a legislação vigente e as boas práticas propostas, sendo importante que todas as recomendações constantes neste trabalho sejam realmente consideradas pela empresa para implantação.

\section{Agradecimentos}

Aos meus pais, Zeno e Hilma, que se mantiveram firmes, apoiando e incentivando incansavelmente toda minha caminhada;

À minha noiva, Lidyane Oleques, pela compreensão e carinho e à sua família, pelo incentivo e afeto;

Ao prof. Raul Oliveira Neto, pela orientação, dedicação e disposição em prol do êxito deste trabalho;

Ao co-orientador, prof. Renato Marques, e aos profs. Luis Eduardo de Sousa, José Rojas e Anelise Schmidt, pela solicitude, atenção e contribuição;

Aos colegas Guilherme Ilha, Gabriel Fontanelli, Ray Forgiarini e Dartanhan Valcarenghi e aos técnicos Marcelo Lusa e Juliana Young, pela colaboração nos trabalhos de campo;

Ao tecnólogo de minas Candido Baptista e a direção e colaboradores da Dagoberto Barcellos S/A, que tornaram possível a realização deste trabalho e

A todos os colegas e professores da Fundação Universidade Federal do Pampa que, de uma forma ou de outra, contribuíram para o êxito deste trabalho.

\section{Referências}

ABNT/ISO 14.001:2004. Sistema de gestão ambiental: requisitos com orientações para uso, Associação Brasileira de Normas Técnicas - ABNT, 27 pág.

ABNT/NBR 13.029: 2006 e 1993- Elaboração e apresentação de projeto de disposição de estéril, em pilha, em mineração, Associação Brasileira de Normas Técnicas - ABNT, 8 pág.

ABNT/NBR 15.495-1: 2007 - Poços de monitoramento de águas subterrâneas em aquíferos granulares. Parte 1: Projeto e construção, Associação Brasileira de Normas Técnicas - ABNT, 25 pág.

ABNT/NBR 15.495-2: 2008 - Poços de monitoramento de águas subterrâneas em aquíferos granulares. Parte 2: Desenvolvimento, Associação Brasileira de Normas Técnicas - ABNT, 24 pág.

ALANO, M. A. V. Pesquisa de calcário - Caieiras, Caçapava do Sul, RS. Relatório final inédito, Porto Alegre. (1977)

BATES, J. Barragens de Rejeitos. 1ª edição. São Paulo: Signus Editora, 122 pág. (2002).

BISHOP, A. W., MORGENSTERN, N. Stability Coefficients for Earth Slopes. Géotechnique, Vol. 10, N 4, pág. 164-169. (1960). 
CPRM - Serviço Geológico do Brasil. Programa Levantamentos Geológicos Básicos do Brasil. Cachoeira do Sul, Folha SH.22-Y-A. Estado do Rio de Grande do Sul. Escala 1:250.000. Organizado por Carlos Alfredo Porcher e Ricardo da Cunha Lopes. Brasília: CPRM. (2000)

DAGOBERTO BARCELLOS. Balanço social, Caçapava do Sul, 2009.

DORNELES, F. T. Controle e Previsão de Vibrações e Ruídos Gerados por Desmonte de Rochas com Explosivos. Trabalho de conclusão de curso, Universidade Federal do Pampa, Tecnologia em Mineração, 96 pág. (2013).

DNPM, Departamento Nacional de Produção Mineral. Normas Regulamentadoras de Mineração NRM 19. Rio de Janeiro, pág. 74 - 82. (2001).

MACIEL FILHO, C. L. Introdução à geologia de engenharia, $3^{\circ}$ ed. atual. Santa Maria: ed. da UFSM, 310 pág. (2008).

MASSAD, F. Obras de Terra: Curso Básico de Geotecnia, $2^{\circ}$ ed. com exercícios resolvidos. São Paulo: ed. Oficina de Textos, 216 pág. (2010).

MICHELE, C. R. B., HERNANI, M. L., ALOISIO, R. P. Um estudo do aumento da resistência ao cisalhamento em solos revegetados com vetiver. 6⿳⺈ CBMina. (2010)

NETO, C. B. V. Aplicação das técnicas de refração e reflexão sísmica em uma área de mineração de calcário em Caçapava do Sul - RS. Universidade Federal do Pampa. Trabalho de conclusão de curso. 63 pág. (2011)

PETRONILHO, M. R. Avaliação do comportamento geotécnico de pilhas de estéril por meio de análise de risco. Dissertação de Mestrado, 137 pág. (2010).

Resolução CONAMA nº 357, de 17 de março de 2005.

SAMPAIO, J. A., ALMEIDA, S. L. M., 2005. Calcário e Dolomito - Capítulo 15. Comunicação Técnica elaborada para Edição do Livro Rochas \& Minerais Industriais: Usos e Especificações Pág. 327 a 350 - CETEM. (2005).

SÁNCHEZ, L. H. Avaliação de impacto ambiental: conceitos e métodos. São Paulo: ed. Oficina de Textos, 495 pág. (2008).

SILVA, A. P. M., VIANA, J. P., CAVAlCANTE, A. L. B. Resíduos Sólidos da Atividade de Mineração. Caderno de Diagnostico, 41 pág. (2011).

SILVA, J. O. Perfil do calcário (Secretaria de Geologia, Mineração e Transformação Mineral - SGM Ministério de Minas e Energia - MME). Relatório Técnico no 38 do Projeto de Assistência Técnica ao Setor de Energia - Projeto ESTAL, 56 pág. (2009).

ZHOU, J., SHI, C, XU, F. Geotechnical Characteristics and Stability Analysis of Rock-Soil Aggregate Slope at the Gushui Hydropower Station, Southwest China. Hindawi Publishing Corporation - The Scientific World Journal. Artigo, 16 pág. (2013). 